\title{
The Influence of the Nature of the Asparagine 289-linked Oligosaccharide on the Activation by Urokinase and Lysine Binding Properties of Natural and Recombinant Human Plasminogens
}

\author{
Donald J. Davidson and Francis J. Castellino \\ Department of Chemistry and Biochemistry, University of Notre Dame, Notre Dame, Indiana 46556
}

\begin{abstract}
Several strategies have been used to obtain recombinant $(r)$ human plasminogens ( $\mathrm{HPg}$ ) containing different oligosaccharide side chains on its sole $\mathbf{N}$-linked glycosylation site, present at Asn289. The approaches included expression of the cDNA for $\mathrm{HPg}$ in insect cell lines under various conditions, addition of glycosidase inhibitors during expression, and purification of specific glycoforms of HPg using affinity chromatography on an insolubilized lectin column. The activation kinetics for urokinase (UK) of each of the purified HPgs, as well as their relative abilities to bind to the ligand, $\epsilon$-aminocaproic acid (EACA), were then determined. Removal of both $\mathrm{N}$ - and $\mathrm{O}$-linked oligosaccharide from HPg resulted in a slight increase in the $\boldsymbol{k}_{\mathrm{cat}} / \boldsymbol{K}_{\mathrm{m}}$ for its activation, while a glycoform containing tetrasialyl-tetraantennary complex oligosaccharide on Asn289 was a slightly poorer substrate for $\mathrm{UK}$ than plasma $\mathrm{HPg}$, which contains bisialyl-biantennary complex carbohydrate on Asn289. The most dramatic differences were observed for HPgs with high mannose-type glycans on Asn289. ( Man $\left._{9} \mathrm{GlCNAc}_{2}\right)$-HPg possessed only $\sim 6 \%$ of the $k_{\text {cat }} / K_{\mathrm{m}}$ of plasma $\mathrm{HPg}$, whereas $\left(\mathrm{Glc}_{3} \mathrm{Man}_{9} \mathrm{GlcNAc}_{2}\right)-\mathrm{HPg}$ did not undergo activation at a significant rate by $\mathrm{UK}$. Differences were also found in the relative abilities of the HPg glycoforms to interact with EACA. The most effective interactions were observed with HPgs containing complex-type glycans, and the least effective binding was found for HPgs with high mannose-type oligosaccharides. The full range of the binding effects is represented by a fourfold difference between $\mathrm{HPg}$ containing tetrasialyl-tetraantennary glycan and $\mathrm{HPg}$ with $\left(\mathrm{Glc}_{3} \mathrm{Man}_{9} \mathrm{GlcNAc}_{2}\right)$ assembled on Asn289.

These results clearly demonstrate that the nature of the $\mathrm{N}$-linked glycan assembled on HPg dramatically influences its ability to be activated by UK and to bind to $\omega$-amino acid effector molecules. (J. Clin. Invest. 1993. 92:249-254.) Key words: cell-specific glycosylation - plasminogen glycoforms • insect cell expressed human plasminogen • plasminogen activation • plasminogen/ligand interactions
\end{abstract}

Address reprint requests to Dr. Francis J. Castellino, Department of Chemistry and Biochemistry, University of Notre Dame, Notre Dame, IN 46556.

Received for publication 6 August 1992 and in revised form 9 February 1993.

J. Clin. Invest.

(C) The American Society for Clinical Investigation, Inc.

0021-9738/93/07/249/06 \$2.00

Volume 92, July 1993, 249-254
Introduction

Human plasminogen $(\mathrm{HPg}),{ }^{1}$ the zymogen form of the serine protease, $\mathrm{HPm}$, is a circulating glycoprotein containing 791 amino acids in a single polypeptide chain (1-5). Activation of $\mathrm{HPg}$ occurs consequent to cleavage of the Arg561-Val562 peptide bond in the zymogen and results in formation of the twochain, disulfide-bond-stabilized, HPm. Activators of HPg include UK, tissue-type plasminogen activator, streptokinase, and staphylokinase (6).

Circulating $\mathrm{HPg}$ can be resolved into two major glycoforms by affinity chromatography on Sepharose-lysine (7). The major differences in these variants are the presence of a bisialylated-biantennary glycan on Asn289 of one form, and the absence of Asn289-linked oligosaccharide on the other $(8,9)$. The identical Thr346-linked trisaccharide is contained on each of the two plasma HPg forms (10).

The glycosylation state of Asn 289 has been shown to influence the functional properties of $\mathrm{HPg}$. The two plasma-derived $\mathrm{HPg}$ variants show differences in their binding properties to $\epsilon$-aminocaproic acid (EACA)-like effector molecules (7) and to fibrin, as well as differences in their activation rates (11) and in the abilities of their corresponding HPm to be inactivated by the fast-acting plasma inhibitor, $\alpha_{2}$-antiplasmin (12). In addition, carbohydrate side chains of $\mathrm{HPg}$ have been shown to be important in its binding to its cellular receptors (13). With the ability to use insect cell lines to express the cDNA for HPg as a variety of glycoforms, thereby providing the opportunity to isolate recombinant $(r) \mathrm{HPg}$ variants with different glycan chains, we believed that it was possible to examine more thoroughly the importance of the HPg oligosaccharide in determining some of its important functional properties, and we summarize the results obtained herein. Few studies of this type have been reported in the literature and are of fundamental importance to understanding protein structure-function relationships. Further, since the oligosaccharides present on proteins are regulated by cell type, cell development, and pathological states of cells, among other factors, an understanding of the role of the carbohydrate in protein function may reveal some of the factors that modulate activities of proteins under various cellular conditions.

1. Abbreviations used in this paper: $\mathrm{DMJ}$, deoxymannojirimycin; $\mathrm{DNJ}$, deoxynojirimycin; EACA, $\epsilon$-amino caproic acid; EF, endo- $\beta$ - $N$-acetylglucosaminidase F; Gal, galactose; GF, peptide $N$-glycohydrolase F; Glc, glucose; HPAEC, high pH anion exchange chromatography; $\mathrm{HPg}$, human plasminogen; ir-HPg, insect cell expressed recombinant human plasminogen; Man, mannose; Sia, sialic acid; SNA, Sambucus nigra agglutinin; UK, urokinase; WGA, wheat germ (Triticum vulgaris) agglutinin. 


\section{Methods}

Proteins. Human plasma $\mathrm{HPg}$ glycoforms 1 and $2(\Delta \mathrm{N}-\mathrm{HPg})$ were isolated from plasma by gradient elution from an affinity chromatography column of Sepharose-lysine as previously described (7).

Recombinant HPg, expressed in IPLB-SF-21AE lepidopteran insect cells, was purified by affinity chromatography on a Sepharose-lysine column. After the desired postinfection times with the r-baculovirus containing the cDNA encoding $\mathrm{HPg}(14)$, the cell-conditioned medium was collected and subjected to centrifugation at $4^{\circ} \mathrm{C}$ for 15 min using a GS- 3 rotor (DuPont, Inc., Wilmington, DE) operating at $5,000 \mathrm{rpm}$. The medium was then lyophilized and the powder redissolved in $50 \mathrm{mM}$ sodium phosphate buffer, $\mathrm{pH} 8.0$, at 0.1 of the original volume. This solution was then percolated over a column $(2.5 \times 30$ $\mathrm{cm}$ ) of Sepharose 6B-L-lysine, equilibrated in $50 \mathrm{mM}$ sodium phosphate, $\mathrm{pH}$ 8.0. The column was washed with this same buffer containing $\mathrm{KCl}(300 \mathrm{mM})$ until the absorbance at $280 \mathrm{~nm}$ was $<0.05$. Bound insect cell expressed recombinant human plasminogen (ir- $\mathrm{HPg}$ ) was then eluted with a buffer containing $50 \mathrm{mM}$ sodium phosphate $/ 200$ $\mathrm{mM}$ EACA, $\mathrm{pH}$ 8.0. After dialysis of the pooled fractions of $\mathrm{r}-\mathrm{HPg}$ against $\mathrm{H}_{2} \mathrm{O}$ at $4^{\circ} \mathrm{C}$, the solution was lyophilized and the purified $\mathrm{r}-\mathrm{HPg}$ stored at $-70^{\circ} \mathrm{C}$.

Low molecular weight two-chain urokinase (UK) (Abbokinase) was provided by Abbott Laboratories (North Chicago, IL). Peptide $N$-glycohydrolase F (GF) and endo- $\beta$ - $N$-acetylglucosaminidase $\mathrm{F}$ (EF), isolated from Flavobacterium meningosepticum, were purchased from Boehringer Mannheim Biochemicals (Indianapolis, IN).

The clam glycosidase mixture, used for total enzymatic digestions of asialyl-oligosaccharides and for removal of O-linked oligosaccharide from $\Delta \mathrm{N}-\mathrm{HPg}$ or $\Delta N$-ir-HPg, was prepared as described previously (15). The fraction used in this investigation was that from the DEAE CL-6B Sepharose anion-exchange chromatography column, which contained at least 16 different glycosidases (15). This mixture was utilized under conditions previously detailed (16). Aspergillus phoenicis $(\alpha 1,2)$-D-mannosidase was obtained from Oxford GlycoSystems (Rosedale, NY).

Preparation of $\mathrm{HPg}$ glycoforms. A variety of methods have been used to produce and purify Asn289-glycosylation variants of $\mathrm{HPg}$ and ir-HPg, including enzymatic deglycosylation, limited exoglycosidase treatment of precursors, and taking advantage of the particular glycoforms produced at different infection times with the r-baculovirus containing the cDNA for HPg. The specific details follow.

$\left(\mathrm{Glc}_{3} \mathrm{Man}_{9} \mathrm{GlcNA}_{2}\right)$-ir-HPg. IPLB-SF-21AE cells were grown as monolayers at a cell density of $1 \times 10^{6}$ cells $/ \mathrm{ml}$ in $150 \mathrm{~cm}^{2}$ flasks in serum-free Excell 400 medium (JRH Biosciences, Lenexa, KS) at $26^{\circ} \mathrm{C}$. When the cells reached $70 \%$ confluency, the medium was removed and replaced with the same medium containing $50 \mu \mathrm{M}$ deoxymannojirimysin (DMJ) and $50 \mu \mathrm{M}$ deoxynojirimycin (DNJ). After 2 $h$, the cells were infected with the r-baculovirus containing the cDNA for HPg at a fourfold multiplicity of infection. The media were collected $60 \mathrm{~h}$ after infection, centrifuged at $7,000 \mathrm{rpm}$ for $15 \mathrm{~min}$, dialyzed against a buffer of $50 \mathrm{mM}$ sodium phosphate, $\mathrm{pH} 8.0$, and lyophilized. Purification of glucose ${ }_{3}$ mannose $_{9} \mathrm{~N}$-acetylglucosamine ${ }_{2}$ $\left(\mathrm{Glc}_{3} \mathrm{Man}_{9} \mathrm{GlcNAc}_{2}\right)$-ir-HPg on Sepharose-lysine solid supports occurred as described above.

$\left(\mathrm{Man}_{9} G l c N A c_{2}\right)-i r-H P g$. The procedure for generation and purification of this glycoform was as described above, except that the only inhibitor added was DMJ $(50 \mu \mathrm{M})$.

$\left(\mathrm{Man}_{5} \mathrm{GlcNAc}_{2}\right)-i r-\mathrm{HPg}$. This glycoform was prepared from purified $\mathrm{Man}_{9} \mathrm{GlcNAc}_{2}$-ir-HPg. Aspergillus phoenicis $(\alpha 1,2)$-D-mannosidase was added to $\left(\mathrm{Man}_{9} \mathrm{GlcNAc}_{2}\right)$-ir- $\mathrm{HPg}$ at a concentration of $2 \mathrm{U}$ of enzyme/mg of substrate. The solution was allowed to incubate for 6-8 $h$ at $37^{\circ} \mathrm{C}$, conditions sufficient for removal of all $(\alpha 1,2)$-linked Man, resulting in $\left(\mathrm{Man}_{5} \mathrm{GlcNAc}_{2}\right)$-ir-HPg.

$\Delta N$-ir- $\mathrm{HPg}$. Lyophilized ir- $\mathrm{HPg}$ was reconstituted in $\mathrm{H}_{2} \mathrm{O}$ at a concentration of $1 \mathrm{mg} / \mathrm{ml}$. Approximately 2-5 U GF/mg of ir- $\mathrm{HPg}$ was added and the solution incubated at $37^{\circ} \mathrm{C}$ for $48-72 \mathrm{~h}$. The mixture was then subjected to centrifugation in a Centricon 10 microconcentrator tube (Amicon, Danvers, MA) to separate the N-linked oligosaccharide from the $\Delta N$-ir-HPg.

$\Delta N, \Delta O-H P g$. Fully deglycosylated plasma $\mathrm{HPg}$ affinity form 2 $(\Delta N-\mathrm{HPg})(7)$ or $\Delta N$-ir-HPg (see above) was accomplished as a consequence of incubation for $12 \mathrm{~h}$ at $25^{\circ} \mathrm{C}$ of the particular $\mathrm{HPg}$ with the DEAE-Sephadex-treated clam liver glycosidase mixture. The reducing terminal GalNAc residue remained bound to $\mathrm{Thr} 346$.

Tetrasialyl-tetraantennary-ir- $\mathrm{HPg}$ was isolated from the population of ir-HPg glycoforms that exist in r-baculovirus/HPg-infected IPLB-SF-21 AE cells at $96 \mathrm{~h}$ after infection. After batch purification of the ir-HPg in this conditioned medium as described above, the protein was treated with $\mathrm{EF}$ ( $1 \mathrm{U} \mathrm{EF} / \mathrm{mg}$ of ir- $\mathrm{HPg}$ ). The remaining ir- $\mathrm{HPg}$ was then passed over an Agarose-Sambucus nigra agglutin (SNA) lectin column (Vector Laboratories, Burlingame, CA) and the tetrasialyltetraantennary-ir- $\mathrm{HPg}$ was eluted with $1 \mathrm{M} \mathrm{NaCl}$.

Oligosaccharide methodology. All methodology used for oligosaccharide determinations, including oligosaccharide mapping and quantitation by high $\mathrm{pH}$ anion exchange chromatography (HPAEC), monosaccharide analyses and quantitation, and wheat germ (Triticum vulgaris) agglutinin (WGA)-dependent visualization of Western blots of $\mathrm{r}-\mathrm{HPg}$, has been described previously $(16,17)$. The oligosaccharide standards used in this investigation were purchased from the Dionex Corporation (Sunnyvale, CA) or Oxford GlycoSystems.

Quantitation of the amount of Asn289-linked oligosaccharide released from a particular glycoform of $\mathrm{HPg}$ or ir-HPg after GF treatment was accomplished by first measuring the ir-HPg concentration $(\epsilon, 1 \%$, $280 \mathrm{~nm}, 1 \mathrm{~cm}=17.0$ ) and completely liberating the Asn289-linked oligosaccharide with GF. The amount of glycan released was determined by the area of its HPAEC peak, and comparison of this to a standard dose-response curve for that particular oligosaccharide. After enzymatic liberation of the monosaccharides from the oligosaccharide with the clam glycosidase mixture, a similar strategy was used for their quantitation.

Comparative binding of $\mathrm{HPg}$ glycoforms to EACA. Approximately 250-300 $\mu \mathrm{g}$ of each purified $\mathrm{HPg}$ and ir- $\mathrm{HPg}$ glycoform dissolved in 50 $\mathrm{mM}$ sodium phosphate, $\mathrm{pH} 8.0$, was applied to a Sepharose-lysine affinity chromatography column at room temperature. The column was then washed with $300 \mathrm{mM}$ sodium phosphate, $\mathrm{pH} 8.0$, to elute possible poorly bound forms. No HPg was eluted under these conditions. A total volume of $30 \mathrm{ml}$ of a linear gradient of EACA (start buffer, 300 $\mathrm{mM}$ sodium phosphate, $\mathrm{pH} 8.0$; limit buffer $300 \mathrm{mM}$ sodium phosphate $/ 25 \mathrm{mM}$ EACA, pH 8.0 ) was applied at a rate of $1 \mathrm{ml} / \mathrm{min}$. Fractions containing $0.5 \mathrm{ml}$ were collected and their absorbancies at $280 \mathrm{~nm}$ were recorded. For identification of the peaks, the oligosaccharide was first removed by GF treatment and then its structure determined by HPAEC and monosaccharide analyses, as described above.

Activation kinetics of the $\mathrm{HPg}$ and ir-HPg glycoforms. Continuous coupled assays of the activation rates of the particular HPgs used were based upon the development of amidolytic activity of the corresponding human plasmin $(\mathrm{HPm})$ that was produced as a result of activation (18). The assays were performed in a 96-well microtiter plate at $25^{\circ} \mathrm{C}$ in a buffer containing $10 \mathrm{mM}$ Hepes- $\mathrm{NaOH} / 100 \mathrm{mM} \mathrm{NaOAc}$, pH 7.4. Final concentrations of assay components were: $\mathrm{HPg}$ or ir- $\mathrm{HPg}(0.2-$ $2.0 \mu \mathrm{M}$ ); $0.5 \mathrm{mM} \mathrm{S} 2251$ (Helena Laboratories, Beaumont, TX); and the required amount of $150 \mathrm{mM} \mathrm{NaOAc}$. Activation was accelerated by addition of $0.5 \mathrm{nM}$ ( final concentration) low molecular weight twochain UK.

Absorbancies resulting from the appearance of $p$-nitroanilide were monitored at $405 \mathrm{~nm}$ with a Thermomax microtiter plate reader (Molecular Devices Corp., Menlo Park, CA) and converted to the concentration of substrate hydrolyzed using an $\epsilon(1 \%, 1 \mathrm{~cm}, 405 \mathrm{~nm})$ of 10,000 . The $K_{\mathrm{m}}$ and $k_{\text {cat }}$ for activation of the HPg or ir-HPg under investigation were calculated as previously described (18).

For calculations of the steady-state activation constants for $\mathrm{HPg}$ by UK, the $K_{\mathrm{m}}$ and $k_{\text {cat }}$ for each HPm toward S2251 are required. These were obtained as follows. Each $\mathrm{HPg}$ or ir- $\mathrm{HPg}$ glycoform was converted to the relevant $\mathrm{HPm}$ or r-HPm with UK (except for 
$\mathrm{Glc}_{3} \mathrm{Man}_{9} \mathrm{GlcNAc}_{2}$-ir-HPg, which was not readily activatable; see below), and their active site concentrations obtained by titration with $p$-nitrophenyl- $p^{\prime}$-guanidinobenzoate (19). The percent of active enzyme obtained ranged from $90-97 \%$ for all activatable glycoforms. The variation of the initial rates of hydrolysis of S2251 as a function of the concentration of $\mathbf{2 2 5 1}$ were determined as above, and the steady-state amidolytic constants were calculated in the usual manner from Lineweaver-Burk plots of the data.

\section{Results}

A number of glycosylation variants of ir-HPg were used to evaluate the effect of the nature of the oligosaccharide assembled on HPg on its ability to be activated by UK and on its ability to interact with $\omega$-amino acid effector molecules, such as EACA. These variants were generated and purified as described in Methods, and the resulting materials displayed single bands on reduced and nonreduced $\mathrm{DodSO}_{4} / \mathrm{PAGE}$. The oligosaccharide was released from each of these proteins by treatment with GF, and the resulting glycan mapped by HPAEC. In all cases, at least $90 \%$ of the plasminogen antigen present in the medium contained releasable oligosaccharide and virtually all oligosaccharide was released from each of the HPg preparations, as revealed by WGA staining of Western blots of the HPg remaining after $\mathrm{GF}$ treatment $(14,16,20)$. Identifications of $\left(\mathrm{Man}_{5} \mathrm{GlcNAc}_{2}\right)$-ir-HPg, ( $\left.\mathrm{Man}_{9} \mathrm{GlcNAc}_{2}\right)$-ir-HPg, ( $\mathrm{Sia}_{2} \mathrm{Gal}_{2}-$ $\mathrm{Man}_{3} \mathrm{GlcNAc}_{4}$ )-ir-HPg (biasialyl-biantennery), and $\left(\mathrm{Sia}_{4} \mathrm{Gal}_{4}\right.$ $\mathrm{Man}_{3} \mathrm{GlcNAc}_{6}$ )-ir-HPg (tetrasialyl-tetraantennary) were made by cochromatography with standard glycans, and on our previous investigations of oligosaccharide assembly on ir- $\mathrm{HPg}$ under different conditions (14, 16, 17, 20). Monosaccharide compositions of complete enzymatic digests of the glycans are presented in Table I and agree fully with the proposed structures. Since a standard oligosaccharide was not available for $\left(\mathrm{Glc}_{3} \mathrm{Man}_{9} \mathrm{GlcNAc}_{2}\right)$, confirmation of this expected glycan structure is based on the results from monosaccharide analysis.

The UK-catalyzed steady-state activation kinetics of each of the glycoforms of ir-HPg were examined. The results obtained are listed in Table II, and are the average of duplicate determinations, which did not differ by more than $10 \%$. Five different substrate $(\mathrm{HPg})$ concentrations were used for analysis with each glycoform, and the standard deviation of the fit for each set of data did not exceed $7 \%$ of the values calculated. The data obtained show the large influence of the nature of the

Table I. Monosaccharide Compositions of the Asn289-linked Glycans Released from the Various Human Plasminogens

\begin{tabular}{lccccc}
\hline & \multicolumn{5}{c}{ Ratio $^{\ddagger}(\mathrm{mol} / \mathrm{mol})$ of: } \\
\cline { 2 - 6 } \multicolumn{1}{c}{ Expected glycoform* } & Sia & Gal & GlcNAc & Glc & Man \\
\hline$\left(\mathrm{Glc}_{3} \mathrm{Man}_{9} \mathrm{GlcNAc}_{2}\right)$ & & & 2.0 & 2.6 & 8.8 \\
$\left(\mathrm{Man}_{9} \mathrm{GlNAc}_{2}\right)$ & & & 2.0 & & 8.8 \\
$\left(\mathrm{Man}_{5} \mathrm{GlcNAc}_{2}\right)$ & & & 2.0 & & 5.1 \\
$\left(\mathrm{Sia}_{2} \mathrm{Gal}_{2} \mathrm{Man}_{3} \mathrm{GlNNAc}_{4}\right)$ & 2.2 & 2.0 & 3.8 & & \\
$\left(\mathrm{Sia}_{4} \mathrm{Gal}_{4} \mathrm{Man}_{3} \mathrm{GlNNAc}_{6}\right)$ & 4.0 & 3.7 & 5.7 & & 3.0
\end{tabular}

* Based upon HPAEC elution as compared with the standard structure listed, and ${ }^{\ddagger}$ Monosaccharide compositions of the $\mathrm{N}$-linked oligosaccharides after digestion with the clam glycosidase mixture, plus $A$. ureafaciens neuraminidase.
Table II. Activation Kinetics of Human Plasminogens Containing Various Asn289-Linked Glycans

\begin{tabular}{|c|c|c|c|}
\hline Plasminogen glycoform & $K_{\mathrm{m}}$ & $k_{\text {cat }}$ & $k_{\mathrm{cal}} / K_{\mathrm{m}}$ \\
\hline & $\mu M$ & $s^{-1}$ & $s^{-1} \mu M^{-1}$ \\
\hline Plasma HPg (bi, $O)^{*}$ & 2.36 & 2.57 & 1.09 \\
\hline Plasma $\operatorname{HPg}(\Delta N, O)^{\ddagger}$ & 1.84 & 2.26 & 1.23 \\
\hline Plasma $\mathrm{HPg}(\Delta N, \Delta O)^{\S}$ & 0.82 & 2.35 & 2.87 \\
\hline ir-HPg $(\Delta N, \Delta O)^{\|}$ & 1.01 & 2.36 & 2.34 \\
\hline ir-HPg $(\Delta N, O)^{1}$ & 1.53 & 3.09 & 2.02 \\
\hline ir- $\mathrm{HPg}\left(\mathrm{Man}_{5} \mathrm{GlcNAc}_{2}, O\right)^{* *}$ & 2.47 & 2.06 & 1.19 \\
\hline ir-HPg $\left(\mathrm{Man}_{9} \mathrm{GlcNAc}_{2}, O\right)^{\ddagger \ddagger}$ & 0.48 & 0.03 & 0.06 \\
\hline ir-HPg $\left(\mathrm{Glc}_{2-3} \mathrm{Man}_{9} \mathrm{GlcNAc}_{2}, O\right)^{\$ s}$ & \multicolumn{3}{|c|}{ No activation observed } \\
\hline ir- $\mathrm{HPg}(\operatorname{tetra}, O)^{\|\|}$ & $8.90^{11}$ & $2.65^{n}$ & 0.30 \\
\hline
\end{tabular}

* Human plasma plasminogen containing bisialyl-biantennary-complex-type oligosaccharide on Asn289 and Thr346-linked oligosaccharide. ${ }^{\ddagger}$ Human plasma plasminogen containing only Thr346-linked oligosaccharide. \$ Aglycosyl-human plasma plasminogen. "Aglycosyl-IPLB-SF-21 AE-expressed human plasminogen. 'IPLB-SF21AE-expressed human plasminogen containing only Thr346-linked oligosaccharide. ${ }^{* *}$ IPLB-SF-21 AE-expressed human plasminogen containing ( $\mathrm{Man}_{9} \mathrm{GlcNAc}_{2}$ ) on Asn289 and Thr346-linked oligosaccharide. ${ }^{\ddagger}$ IPLB-SF-21AE-expressed human plasminogen containing $\left(\mathrm{Man}_{5} \mathrm{GlcNAc}_{2}\right)$ on Asn289 and Thr346-linked oligosaccharide. $\$$ IPLB-SF-21AE-expressed human plasminogen containing $\left(\mathrm{Glc}_{3} \mathrm{Man}_{9} \mathrm{GlcNAc}_{2}\right.$ ) on Asn 289 and Thr346-linked oligosaccharide. "I II IPLB-SF-21 AE-expressed human plasminogen containing tetrasialyl-tetraantennary complex-type oligosaccharide on Asn289 and Thr346-linked oligosaccharide. "The $K_{\mathrm{m}}$ and $k_{\text {cat }}$ values for activation of this glycoform must be viewed as estimates since the highest plasminogen concentrations used (these are limited by the solubility of the plasminogen) are $\sim 2 \mu \mathrm{M}$. The $k_{\text {cal }} / K_{\mathrm{m}}$ value, however, remains accurate.

$N$-linked glycan present at Asn289 on the activation kinetics of $\mathrm{HPg}$, the most dramatic of which is the resistance of $\left(\mathrm{Glc}_{3} \mathrm{Man}_{9} \mathrm{GlcNAc}_{2}\right)$-ir-HPg toward activation by UK. For calculation of the steady state activation constants, the $K_{\mathrm{m}}$ and $k_{\text {cat }}$ for the respective HPm toward amidolysis of the substrate, $\mathrm{S} 2251$, were required. These values have been determined on each of the fully activated HPm samples (except for $\mathrm{Glc}_{3} \mathrm{Man}_{9} \mathrm{GlcNAc}_{2}$-ir-HPg, which was not analyzed since it could not be readily activated), and were used in the calculations. No substantial kinetic differences were found between the various plasmins for hydrolysis of this substrate. The $K_{\mathrm{m}}$ values obtained ranged from 0.26 to $0.34 \mathrm{mM}$, and the $k_{\text {cat }}$ values were $14.3-16.7 \mathrm{~s}^{-1}$.

Since the ir-HPg samples were insect derived and were being compared with plasma HPg glycoforms, we needed to evaluate whether possible cell-specific folding of the protein could have influenced the results. Therefore, we completely deglycosylated with GF all $\mathrm{HPg}$ samples used and determined UK activation kinetics for each of the resulting proteins. The data obtained are provided in Table III. It is clear that fully deglycosylated ir-HPg expressed in the IPLB-SF-21AE cells used herein, as well as other variety of insect cell lines, viz, CM-1, SF-9, and IZD-MBO503, all show similar activation kinetics with UK, which are also very similar to the deglycosylated plasma HPg. Thus, the differences in these kinetic parameters observed in the glycosylated proteins are indeed related to the 
Table III. Activation Kinetics of Aglycosyl-Human Plasminogens Expressed in Different Lepidopteran Insect Cell Lines

\begin{tabular}{lccc}
\hline \multicolumn{1}{c}{ Plasminogen } & $K_{\mathrm{m}}$ & $k_{\text {cat }}$ & $k_{\text {cal }} / K_{\mathrm{m}}$ \\
\hline & $\mu M$ & $s^{-1}$ & $s^{-1} \mu M^{-1}$ \\
& & & \\
Plasma $\operatorname{HPg}(\Delta N, \Delta O)^{*}$ & 1.00 & 2.15 & 2.15 \\
CM-1-r-HPg $(\Delta N, \Delta O)^{\ddagger}$ & 1.00 & 2.27 & 2.27 \\
IZD-MBO503-r-HPg $(\Delta N, \Delta O)^{\S}$ & 0.99 & 2.47 & 2.49 \\
SF-9-r-HPg $(\Delta N, \Delta O)^{\|}$ & 1.03 & 2.33 & 2.26 \\
IPLB-SF-21AE-rHPg $(\Delta N, \Delta O)^{11}$ & 1.11 & 2.15 & 2.06 \\
& & & \\
& & &
\end{tabular}

* Human plasma plasminogen. ${ }^{\ddagger}$ Recombinant human plasminogen expressed in Manduca sexta cells. ${ }^{8}$ Recombinant human plasminogen expressed in Mamestra brassicae cells. "Recombinant human plasminogen expressed in Spodoptera frugiperda cells. 'Recombinant human plasminogen expressed in Spodoptera frugiperda cells.

nature of the glycan, and not to inherent differences in the r-HPg that may result from expression in different cell lines.

Finally, we examined the relative abilities of each of the ir-HPg preparations to interact with the activation effector molecule, EACA. This comparative study was accomplished by preparing a cocktail of the proteins, adsorbing this mixture to a Sepharose-lysine affinity chromatography column, and eluting the proteins with a gradient of EACA. The elution profile is illustrated in Fig. 1, and the concentrations of EACA at the points of maximum absorbancies of the peaks are provided in Table IV. Identification of the glycan structures present in each of pools that were eluted from the Sepharose-lysine column was accomplished by HPAEC chromatography, along with appropriate oligosaccharide standards. The HPAEC maps of each of the glycans are shown in Fig. 2 and resulted in very clear identifications of the oligosaccharides present on each of the protein fractions. Fraction C of Fig. 1 did not contain oligosaccharide, suggesting the absence of Asn-linked glycosylation on this fraction. In addition, the peak area of fraction $C$ was ap-

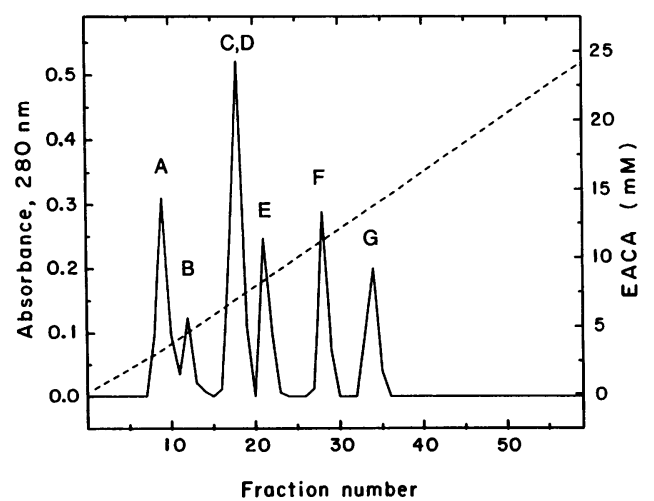

Figure 1. Elution profile of $\mathrm{HPg}$ glycoforms from a Sepharose-lysine affinity chromatography column using a gradient of EACA. The seven glycoforms applied in a cocktail were:

$\left(\mathrm{Sia}_{4} \mathrm{Gal}_{4} \mathrm{GlcNAc}_{4} \mathrm{Man}_{3} \mathrm{GlcNAc}_{2}\right)$-ir-HPg,

$\left(\mathrm{Sia}_{2} \mathrm{Gal}_{2} \mathrm{GlcNAc}_{2} \mathrm{Man}_{3} \mathrm{GlcNAc}_{2}\right)-\mathrm{HPg},(\Delta N)-\mathrm{HPg},(\Delta N, \Delta O)-\mathrm{HPg}$, $\left(\mathrm{Man}_{9} \mathrm{GlcNAc}_{2}\right)$-ir-HPg, $\left(\mathrm{Glc}_{3} \mathrm{Man}_{9} \mathrm{GlcNAc}_{2}\right)$-ir- $\mathrm{HPg}$, and $\left(\mathrm{Man}_{5} \mathrm{GlcNAc}_{2}\right)$-ir-HPg. The dashed line is the progress of the linear gradient of EACA. The buffer employed was $300 \mathrm{mM}$ sodium phosphate, pH 8.0.
Table IV. Relative Binding to Sepharose-lysine Columns of Human Plasminogens Containing Various N289-linked Glycans

\begin{tabular}{|c|c|c|}
\hline Column fraction* & Plasminogen glycoform ${ }^{t}$ & $C_{\max }^{8}$ \\
\hline & & $m M$ \\
\hline A & $\left(\mathrm{Sia}_{4} \mathrm{Gal}_{4} \mathrm{GlcNAc}_{4} \mathrm{Man}_{3} \mathrm{GlcNAc}_{2}\right)$-ir- $\mathrm{HPg}$ & 3.33 \\
\hline B & $\left(\mathrm{Sia}_{2} \mathrm{Gal}_{2} \mathrm{GlcNAc}_{2} \mathrm{Man}_{3} \mathrm{GlcNAc}_{2}\right)-\mathrm{HPg}$ & 4.58 \\
\hline $\mathrm{C}$ & $\operatorname{HPg}(\Delta N, \Delta O)$ & 7.08 \\
\hline D & $\operatorname{HPg}(\Delta N)$ & 7.08 \\
\hline $\mathrm{E}$ & $\left(\mathrm{Man}_{5} \mathrm{GlcNAc}_{2}\right)$-ir-HPg & 8.33 \\
\hline $\mathbf{F}$ & $\left(\mathrm{Man}_{9} \mathrm{GlcNAc}_{2}\right)$-ir-HPg & 11.25 \\
\hline G & $\left(\mathrm{GlcMan}_{9} \mathrm{GlcNAc}_{2}\right)$-ir-HPg & 13.75 \\
\hline
\end{tabular}

* From Fig. 2. ${ }^{\ddagger}$ The monosaccharide contents of the $N$-linked oligosaccharides released by glycopeptidase $F$. ${ }^{\S}$ The concentration of EACA at the maximal absorbance of the indicated eluted column fraction.

proximately twofold greater than any of the other components eluted, suggesting that two proteins are present in this pool. Thus, peak $\mathrm{C}$ was assigned to both ir- $\mathrm{HPg}(\Delta N)$ and ir- $\mathrm{HPg}$ $(\Delta N, \Delta O)$, and labeled as peak $\mathrm{C}, \mathrm{D}$ in Fig. 1. These identifications were verified by addition to the column and elution of each of these samples individually, under the same conditions. Their elution positions were virtually the same.

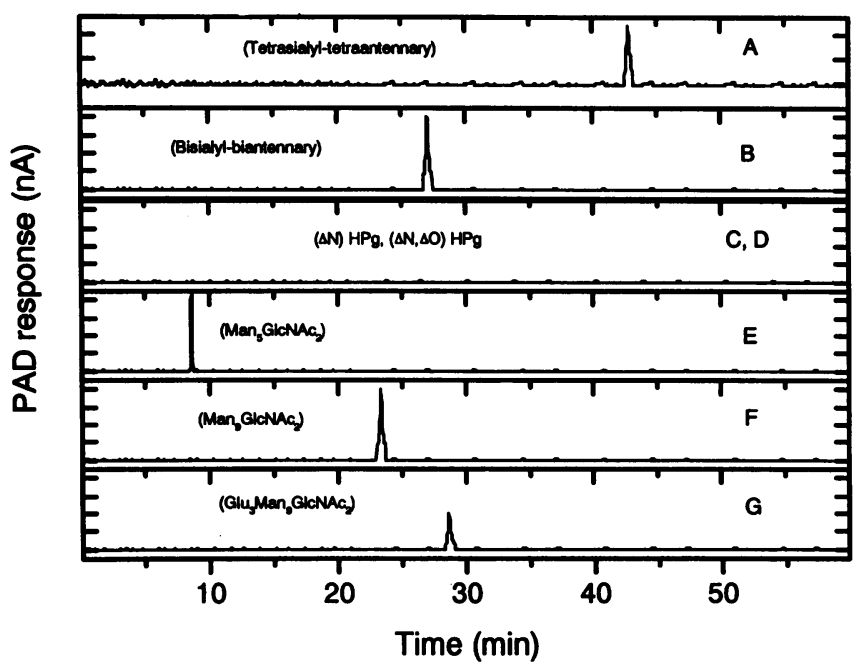

Figure 2. HPAEC profiles of the N-linked oligosaccharides released from the various $\mathrm{HPg}$ glycoforms eluted from the Sepharose-lysine column of Fig. 1. The gradient used for separations is the same for each of the samples and utilized mixtures of solutions $A(200 \mathrm{mM}$ $\mathrm{NaOH}), \mathrm{B}(1 \mathrm{mM} \mathrm{NaOH})$, and $\mathrm{C}(1 \mathrm{M} \mathrm{NaOAc})$. The column, Carbopac PA1 $(4 \times 250 \mathrm{~mm})$, was equilibrated with a mixture of $50 \%$ solvent $\mathrm{A} / 47 \%$ solvent $\mathrm{B} / 3 \%$ solvent $\mathrm{C}$. After application of this solution for $15 \mathrm{~min}$, a linear gradient of $50 \%$ solvent $A / 47 \%$ solvent $\mathrm{B} / 3 \%$ solvent $\mathrm{C}$ (start solution) to $50 \%$ solvent $\mathrm{A} / 25 \%$ solvent $\mathrm{B} / 25 \%$ solvent $\mathrm{C}$ (limit solvent) was used up to $30 \mathrm{~min}$ total time. The limit solvent was then continued for an additional $15 \mathrm{~min}$. The flow rate was $1 \mathrm{ml} / \mathrm{min}$ at room temperature. The fractions refer to those of Fig. 1, and the glycan representations are based upon comparison of retention times with standard oligosaccharides, except for $\left(\mathrm{Glc}_{3} \mathrm{Man}_{9} \mathrm{GlcNAc}_{2}\right)$, the identification of which was made by monosaccharide analysis of a total enzymic hydrolysis of the oligosaccharide. 


\section{Discussion}

We have used a variety of strategies to control the nature of the carbohydrate assembled on Asn 289 of $\mathrm{HPg}$, and to isolate subpopulations of this protein containing a defined and singular glycan at this position. Addition of the inhibitors DNJ and DMJ to the insect culture media provided exclusively r-HPgs containing $\left(\mathrm{Glc}_{3} \mathrm{Man}_{9} \mathrm{GlcNAc}_{2}\right)$ and $\left(\mathrm{Man}_{9} \mathrm{GlcNAc}_{2}\right)$ at position Asn289, and digestion of the $\left(\mathrm{Man}_{9} \mathrm{GlcNAc}_{2}\right)$-ir- $\mathrm{HPg}$ with Aspergillus phoenicis ( $\alpha 1,2)$-D-mannosidase provided $\left(\mathrm{Man}_{5} \mathrm{GlcNAc}_{2}\right)$-ir-HPg. Plasma HPg, glycoform 1 (7) is well known to contain biantennary-bisialyl glycan as its only $N$ linked oligosaccharide, and thus was the source of this particular glycoform. The pool of ir-HPg was enriched in tetraantennary-tetrasialylated glycan by allowing expression to proceed for long infection times (14). EF was then added to cleave the high mannose and biantennary-complex glycans, which were removed from the pool by dialysis. Next, sialic acid-containing ir-HPg pools were adsorbed to a SNA lectin-agarose column, and a fraction containing tetrasialylated-tetraantennary-ir$\mathrm{HPg}$ was eluted with $\mathrm{NaCl}$. Asn289-deglycosylated $\mathrm{HPg}$ was obtained as glycoform 2 of plasma $\mathrm{HPg}(7)$, or by treatment of the ir-HPg pools with GF, and the O-linked sugars (except for the reducing-terminal GalNAc) were removed from Thr346 of plasma HPg by treatment of the $N$-aglycosyl protein with a clam exoglycosidase mixture (15).

With these samples, which represent most of the major classes of glycan structures assembled on proteins, we were in an excellent position to investigate the effect of the oligosaccharide on some of the important functional properties of $\mathrm{HPg}$. Unfortunately, one group of glycans not represented are the hybrid oligosaccharides, but as a result of investigating several r-HPg expression systems, viz, CHO cells (17), IPLB-SF-21AE cells (14), IZD-MBO503 cells (14), and SF-9 cells (21), we do not find any glycan structures containing a bisecting GlcNAc. This suggests that r-HPg may not be a good substrate for the enzyme, $\mathrm{N}$-acetylglucosammyltransferase III.

UK-catalyzed activation kinetics of all the HPg samples described here have been performed and the steady-state kinetic parameters obtained are provided in Table II. These investigations were performed in a $\mathrm{Cl}^{-}$-free buffer because of the inhibitory effects of $\mathrm{Cl}^{-}$on the activation of $\mathrm{Glu}^{1}$-plasminogen (22). The plasminogens isolated were mixtures of $\mathrm{Glu}^{1}$-plasminogen and Lys ${ }^{78}$-plasminogen. In the absence of $\mathrm{Cl}^{-}$, both forms of plasminogen activate at the same rate, where $\mathrm{Glu}^{1}$ plasminogen behaves functionally as $\mathrm{Lys}^{78}$-plasminogen (22). From the results obtained, clearly the nature of the carbohydrate assembled on Asn289 plays a major role in this functional property of $\mathrm{HPg}$. In comparing the r-HPg containing the naturally occurring bisialyl-biantennary glycan with its $\mathrm{N}$-deglycosylated analogue, a very slight inhibition of activation occurs with the glycosylated form. Removal of the Thr346-linked trisaccharide (10) also results in a slight stimulation of activation, as is also the case with the ir- $\mathrm{HPg}$, albeit to a lesser extent, an observation perhaps related to the differences in the nature of the O-linked sugars assembled on human plasma vs. ir-HPg. However, none of these effects are very dramatic. Much more significant changes occur when the nature of the N-linked glycan located at Asn289 is considered. In proceeding to a higher branched complex-type oligosaccharide, tetrasialyl-tetraantennary-ir- $\mathrm{HPg}$, there is a large increase (approximately fourfold) in the $K_{\mathrm{m}}$ for activation, with essentially no alteration in the $k_{\text {cat }}$ value. Thus, a nearly fourfold activation rate decrease occurs with the more highly branched complex-type glycan. With regard to the high mannose forms of ir- $\mathrm{HPg}$, the $\left(\mathrm{Man}_{9} \mathrm{GlcNAc}_{2}\right)$-containing glycoform is activated much more slowly $(\sim 5 \%)$ than the rate of plasma $\mathrm{HPg}$, solely due to the large decrease of the $k_{\text {cat }}$ of the activation reaction, and the untrimmed glycoform, $\left(\mathrm{Glc}_{3} \mathrm{Man}_{9} \mathrm{GlcNAc}_{2}\right)$-ir- $\mathrm{HPg}$, does not undergo activation by $\mathrm{UK}$ at a significant rate. The partially trimmed high mannose variant, $\left(\mathrm{Man}_{5} \mathrm{GlcNAc}_{2}\right)$-ir- $\mathrm{HPg}$, is activated at a rate equivalent to that of plasma $\mathrm{HPg}$. Thus, it is concluded that the nature of the Asn289-linked oligosaccharide assembled on $\mathrm{r}-\mathrm{HPg}$ greatly affects the ability of this protein to be activated by UK. This is most reasonably explained by the differing nature of the oligosaccharide-protein interactions that occur with complex-type oligosaccharides and high mannose-type oligosaccharides with the HPg or the kinetically relevant $\mathrm{r}-\mathrm{HPg} / \mathrm{UK}$ complexes, the specific natures of which are not known. The physiologically relevant glycosylated form of $\mathrm{HPg}$, viz, $\left(\mathrm{Sia}_{2} \mathrm{Gal}_{2} \mathrm{Man}_{3} \mathrm{GlcNAc}_{4}\right)-\mathrm{HPg}$, activates most efficiently, and its $\mathrm{N}$-deglycosylated form, which represents approximately one half of the circulating $\mathrm{HPg}$, also is activated quite efficiently. Other glycoforms of $\mathrm{HPg}$, which may be present in disease states or at different stages of cellular differentiation, may serve as an excellent control vehicle for production of the fibrinolytic state. The best known example is that of neonates. It has been found that a defective fibrinolytic potential exists in neonatal plasma (23). This clinical state has been correlated with the altered glycosylation of neonatal $\mathrm{HPg}$, wherein one glycoform that is heavily mannosylated and another that is extensively polysialylated have been isolated from neonatal plasma (24). Both of the neonatal glycoforms exhibit weaker binding to cellular receptors on U937 cells than adult $\mathrm{HPg}$, and also display defective steady-state activation kinetic parameters in a tissue-type plasminogen activator/fibrinogen fragment activation system (24).

Another functional property that is affected by the nature of the glycosylation state of $\mathrm{HPg}$ is its ability to bind to the effector molecule, EACA. $\omega$-amino acids of this type interact with kringle regions in the noncatalytic polypeptide chain of $\mathrm{HPg}$, and thereby produce complex effects on HPg structure and function. As a result of interaction of $\mathrm{HPg}$ with $\omega$-amino acids, a large conformational alteration takes place in HPg (25), allowing its activation rate to become greatly enhanced (26). This leads to a fibrinolytic potential. In vivo, an opposing effect also occurs, in that EACA-like compounds inhibit the binding of $\mathrm{HPg}$ and $\mathrm{HPm}$ to fibrin (27), thereby producing an antifibrinolytic state. We first demonstrated that the interaction of EACA with $\mathrm{HPg}$ was influenced by the presence of carbohydrate on Asn289 (7), since the aglycosylated form ( HPg- $\Delta N$ ) interacted more weakly with EACA than its aglycosyl counterpart. The current investigation demonstrates that the nature of the Asn289-linked oligosaccharide also plays a great role in the ability of $\mathrm{HPg}$ to interact with EACA. The data of Table IV demonstrate that high mannose-type glycoforms of $\mathrm{r}-\mathrm{HPg}$ interact more weakly with EACA, while complextype glycoforms bind more tightly to EACA. Thus, this important functional property of HPg is also dependent upon the nature of the oligosaccharide assembled on Asn289 of r-HPg, and this could be an important control feature of the production of a fibrinolytic or antifibrinolytic state in conditions where the glycosylation assembly mechanisms of cells are different from their normal mature state. 
This investigation, among the first of its kind that makes use of differing cell expression strategies to systematically place defined and varied oligosaccharide side chains on a recombinant protein, demonstrates the importance of the nature of the oligosaccharide that is assembled on $\mathrm{HPg}$ to its functional properties. Alteration of normal glycosylation pathways during cell development or in pathological conditions could lead to an altered fibrinolytic state, with its concomitant important ramifications on the organism as a whole.

\section{Acknowledgments}

This work was supported by grant HL-13423 from the National Institutes of Health, the Kleiderer/Pezold Family endowed professorship (to F. J. Castellino), and the Grace Foundation Graduate Fellowship (to D. J. Davidson).

\section{References}

1. Wiman, B. 1973. Primary structure of peptides released during activation of human plasminogen by urokinase. Eur. J. Biochem. 39:1-9.

2. Wiman, B. 1977. The primary structure of the $\beta$ (light) chain of human plasmin. Eur. J. Biochem. 76:129-137.

3. Sottrup-Jensen, L., H. Claeys, M. Zajdel, T. E. Petersen, and S. Magnusson. 1978. The primary structure of human plasminogen: isolation of two lysine-binding fragments and one "mini" plasminogen (MW, 38000) by elastase-catalyzedspecific limited proteolysis. Prog. Chem. Fibrinolysis Thrombolysis. 3:191-209.

4. Malinowski, D. P., J. E. Sadler, and E. W. Davie. 1984. Characterization of a complementary DNA coding for human and bovine plasminogen. Biochemistry. 23:4243-4250.

5. Forsgren, M., B. Raden, M. Israelsson, K. Larsson, and L.-O. Heden. 1987 Molecular cloning and characterization of a full-length cDNA clone for human plasminogen. FEBS (Fed. Eur. Biochem. Soc.) Lett. 213:254-260.

6. Castellino, F. J. 1983. Plasminogen activators. Bioscience. 33:647-650.

7. Brockway, W. J., and F. J. Castellino. 1972. Measurement of the binding of antifibrinolytic amino acids to various plasminogens. Arch. Biochem. Biophys. 151:194-199.

8. Hayes, M. L., and F. J. Castellino. 1979. Carbohydrate of human plasminogen variants. I. Carbohydrate composition and glycopeptide isolation and characterization. J. Biol. Chem. 254:8768-8771.

9. Hayes, M. L., and F. J. Castellino. 1979. Carbohydrate of human plasminogen variants. II. Structure of the asparagine-linked oligosaccharide unit. J. Biol. Chem. 254:8772-8776.

10. Hayes, M. L., and F. J. Castellino. 1979. Carbohydrate of human plasminogen variants. III. Structure of the O-glycosidically-linked oligosaccharide unit. $J$. Biol. Chem. 254:8777-8780.

11. Takada, A., and Y. Takada. 1983. The activation of two isozymes of glu-plasminogen (I and II) by urokinase and streptokinase. Thromb. Res. 30:633-642.

12. Wiman, B., L. Boman, and D. Collen. 1978. On the kinetics of the interaction between human antiplasmin and a low-molecular-weight form of plasmin. Eur. J. Biochem. 87:143-146.

13. Gonzalez-Gronow, M., J. M. Edelberg, and S. V. Pizzo. 1989. Further characterization of the cellular plasminogen binding site: Evidence that plasminogen 2 and lipoprotein a compete for the same site. Biochemistry. 28:2374-2377.

14. Davidson, D. J., and F. J. Castellino. 1991. Asparagine-linked oligosaccharide processing in lepidopteran insect cells. Temporal dependence of the nature of the oligosaccharides assembled on asparagine 289 of recombinant human plasminogen produced in baculovirus vector-infected Spodoptera frugiperda (IPLBSF-21AE) cells. Biochemistry. 30:6167-6174.

15. Ghosh, S., S. Lee, T. A. Brown, M. Basu, J. W. Hawes, D. Davidson, and S. Basu. 1991. Use of exoglycosidases from Mercenaria mercenaria (hard shelled clam) as a tool for structural studies of glycosphingolipids and glycoproteins. Anal. Biochem. 196:252-261.

16. Davidson, D. J., M. J. Fraser, and F. J. Castellino. 1990. Oligosaccharide processing in the expression of human plasminogen cDNA by lepidopteran insect (Spodoptera frugiperda) cells. Biochemistry. 29:5584-5590.

17. Davidson, D. J., and F. J. Castellino. 1991. Oligosaccharide structures present on asparagine 289 of recombinant human plasminogen expressed in a Chinese hamster ovary cell line. Biochemistry. 30:625-633.

18. Urano, T., V. S. de Serrano, B. A. K. Chibber, and F. J. Castellino. 1987. The control of the urokinase-catalyzed activation of human glutamic acid 1-plasminogen by positive and negative effectors. J. Biol. Chem. 262:15959-15964.

19. Chase, T., and E. Shaw. 1969. Comparison of the esterase activities of trypsin, plasmin, and thrombin on guanidino esters. Titration of the enzymes. Biochemistry 8:2212-2224.

20. Davidson, D. J., and F. J. Castellino. 1991. Structures of the Asn 289linked oligosaccharides assembled on recombinant human plasminogen expressed in a Mamestra brassicae cell line (IZD-MBO503). Biochemistry. 30:6689-6696.

21. Castellino, F. J., D. J. Davidson, E. Rosen, and J. McLinden. 1992. Expression of human plasminogen cDNA in lepidopteran insect cells and analysis of the asn-linked glycosylation patterns of the recombinant plasminogens. Methods Enzymol. In press.

22. Urano, T., V. S. De Serrano, B. A. K. Chibber, and F. J. Castellino. 1987. The control of the urokinase-catalyzed activation of human glutamic acid 1-plasminogen by positive and negative effectors. J. Biol. Chem. 262:15959-15964.

23. Schmidt, B., and A. Zipursky. 1984. Thrombolytic disease in newborn infants. Clin. Perinatol. 11:461-485.

24. Edelberg, J. M., J. Enghild, S. V. Pizzo, and M. Gonzalez-Gronow. 1990. Neonatal plasminogen displays altered cell surface binding and activation kinetics. Correlation with increased glycosylation of the protein. J. Clin. Invest. 86:107-112.

25. Violand, B. N., J. M. Sodetz, and F. J. Castellino. 1975. The effect of epsilon amino caproic acid on the gross conformation of plasminogen and plasmin. Arch. Biochem. Biophys. 170:300-305.

26. Claeys, H., and J. Vermylen. 1974. Physicochemical and proenzyme properties of amino-terminal glutamic acid and amino-terminal lysine human plasminogen. Biochim. Biophys. Acta. 342:351-359.

27. Thorsen, S. 1975. Differences in binding to fibrin of native plasminogen and plasminogen modified by proteolytic degradation. Biochim. Biophys. Acta 393:55-65. 